HEALTHCARE DELIVERY

\title{
Anterior chamber paracentesis to improve diagnosis and treatment of infectious uveitis in South Africa
}

\begin{abstract}
E Schaftenaar, K A Lecuona, G S Baarsma, C Meenken, G M G M Verjans, J A McIntyre, R P H Peters
Dr Erik Schaftenaar, MD, is a PhD candidate in the Department of Viroscience, Erasmus MC, Rotterdam, The Netherlands, a resident in ophthalmology at Rotterdam Eye Hospital, and an honorary research associate at Anova Health Institute, Tzaneen, South Africa. The clinical studies for his thesis are part of the 'Mopani Eye Project', a collaboration between Anova Health Institute and the Department of Viroscience. Dr Karin Lecuona, MD, is an ophthalmologist in the Department of Ophthalmology, Groote Schuur Hospital and Faculty of Health Sciences, University of Cape Town, South Africa. Dr Seerp Baarsma, MD, is an ophthalmologist, specialised in uveitis and the medical retina, and works for the Rotterdam Ophthalmic Institute, The Netherlands. Dr Christina Meenken, MD, PhD, is an ophthalmologist with a special interest in uveitis and HIV/AIDS ophthalmology and works at the VU University Medical Center, Amsterdam, The Netherlands. Prof. Georges Verjans, MSc, PhD, is head of the Herpes Research Group at the Department of Viroscience, Erasmus MC, and an affiliated professor at the Research Center for Emerging Infections and Zoonoses, University of Veterinary Medicine, Hanover, Germany. Prof. James McIntyre, MB ChB, FRCOG, is Executive Director of the Anova Health Institute and an honorary professor affiliated to the School of Public Health and Family Medicine, Faculty of Health Sciences, University of Cape Town. Prof. Remco Peters, MD, PhD, DLSHTM, works for Anova Health Institute as clinical programme specialist and is an affiliated extraordinary professor in the Department of Medical Microbiology, Faculty of Health Sciences, University of Pretoria, South Africa.
\end{abstract}

Corresponding author: E Schaftenaar (e.schaftenaar@gmail.com)

Infectious uveitis is a significant cause of blindness in South Africa, especially among HIV-infected individuals. The visual outcome of uveitis depends on early clinical and laboratory diagnosis to guide therapeutic intervention. Analyses of aqueous humor obtained by anterior chamber paracentesis direct the differential diagnosis in infectious uveitis. However, although safe and potentially cost-effective, diagnostic anterior chamber paracentesis is not common practice in ophthalmic care across Africa. We draw attention to this important procedure, which could improve the diagnosis and prognosis of infectious uveitis.

S Afr Med J 2015;105(8):628-630. DOI:10.7196/SAMJnew.7816

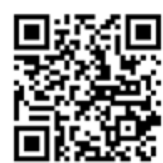

Uveitis is a potentially sightthreatening eye condition with an estimated prevalence of up to $714 / 100000$ in the developing world. ${ }^{[1]}$ HIV impacts on the burden of uveitis, as HIVinfected individuals have increased susceptibility to ocular infections and may present with more severe disease. ${ }^{[1,2]}$ In Uganda, infectious uveitis is the most common cause (41\%) of non-correctable visual impairment among HIV-infected individuals. ${ }^{[3]}$ In sub-Saharan Africa, including countries where onchocerciasis is endemic, up to $25 \%$ of all blindness can be attributed to uveitis. ${ }^{[1]}$ Uveitis has a wide range of causes, with an infectious origin in up to $50 \%$ of cases in Africa. ${ }^{[1]}$

\section{Diagnostic challenges in uveitis}

Early diagnosis and subsequent initiation of targeted antimicrobial treatment is vitally important for good visual outcome in patients with infectious uveitis. ${ }^{[4-6]}$ However, accurate diagnosis is challenging, especially in resource-poor settings and in HIVinfected individuals. ${ }^{[2,3]}$ Firstly, uveitis is generally clinically underdiagnosed owing to lack of ophthalmological expertise. ${ }^{[2]}$
Unrecognised uveitis was reported to result in significant visual impairment among Ugandan HIV-infected individuals. ${ }^{[3]}$ Visual impairment in these cases could possibly have been prevented if the condition had been recognised early. Secondly, if uveitis is diagnosed clinically, the presumed cause may be incorrect as the diagnosis is based on the patient's history and clinical and ophthalmological characteristics. Clinical features have poor predictive value for diagnosing the cause of uveitis, and do not distinguish well between infectious and non-infectious origin. Moreover, in cases of infectious uveitis, clinical features are poorly predictive of the causative pathogen, because different pathogens may present with similar clinical characteristics. ${ }^{[4,5]}$ Based on diagnostic testing in almost a quarter of patients presenting with uveitis in studies from The Netherlands and South Africa (SA), the initial clinical diagnosis was adjusted and treatment altered. ${ }^{[4,5]}$ An exception may be uveitis caused by Mycobacterium tuberculosis where the patient's history (e.g. recent history of pulmonary tuberculosis) or specific retinal findings (e.g. granuloma) are strongly indicative of infection by this organism. However, tuberculosis cannot always be ruled out solely on the basis of clinical symptoms. ${ }^{[7]}$ Thirdly, empirical treatment of infectious uveitis is difficult because of the wide range of potential uveitogenic pathogens that require targeted treatment (Table 1). Finally, HIV-infected individuals are at an increased risk of specific opportunistic ocular infections (e.g. cytomegalovirus retinitis). ${ }^{[2]}$ Manifestations of infectious uveitis are often atypical, with immunosuppression resulting in a lower degree of inflammation, even in advanced uveitis, compared with HIVuninfected individuals. This makes clinical identification of the triggering pathogen in HIV-infected individuals particularly challenging. ${ }^{[2]}$

\section{Diagnostic analysis of aqueous humor}

The clinical diagnosis of infectious uveitis is increasingly supported in Western countries by analysis of ocular fluid $^{[8]}$ obtained through diagnostic anterior chamber paracentesis and aspiration of aqueous humor (Fig. 1). This is a well-documented procedure that is routinely performed in other aspects of ophthalmological care, e.g. management of acute elevation 
Table 1. Clinical management of the most common pathogens in infectious uveitis

\begin{tabular}{|c|c|}
\hline Aetiology & Treatment \\
\hline \multicolumn{2}{|l|}{ Viruses } \\
\hline HSV and VZV & $\begin{array}{l}\text { Topical and oral or intravenous antivirals (e.g. acyclovir), } \\
\text { topical corticosteroids (e.g. prednisolone acetate eyedrops), and } \\
\text { intravitreal antiviral agents (e.g. ganciclovir) }\end{array}$ \\
\hline CMV & Intravenous and/or intravitreal antiviral agents (e.g. ganciclovir) \\
\hline \multicolumn{2}{|l|}{ Bacteria } \\
\hline $\begin{array}{l}\text { Mycobacterium } \\
\text { tuberculosis }\end{array}$ & $\begin{array}{l}\text { Routine treatment for extrapulmonary tuberculosis and topical } \\
\text { steroids (e.g. prednisolone acetate eyedrops) }\end{array}$ \\
\hline Treponema pallidum & $\begin{array}{l}\text { Intravenous antibiotic treatment (e.g. penicillin } \mathrm{G} \text { or } \\
\text { ceftriaxone) }\end{array}$ \\
\hline \multicolumn{2}{|l|}{ Protozoa } \\
\hline Toxoplasma gondii & $\begin{array}{l}\text { Oral antimicrobial regimens (e.g. pyrimethamine) and systemic } \\
\text { steroids (e.g. prednisolone) }\end{array}$ \\
\hline Onchocerca volvulus & Oral ivermectin \\
\hline
\end{tabular}

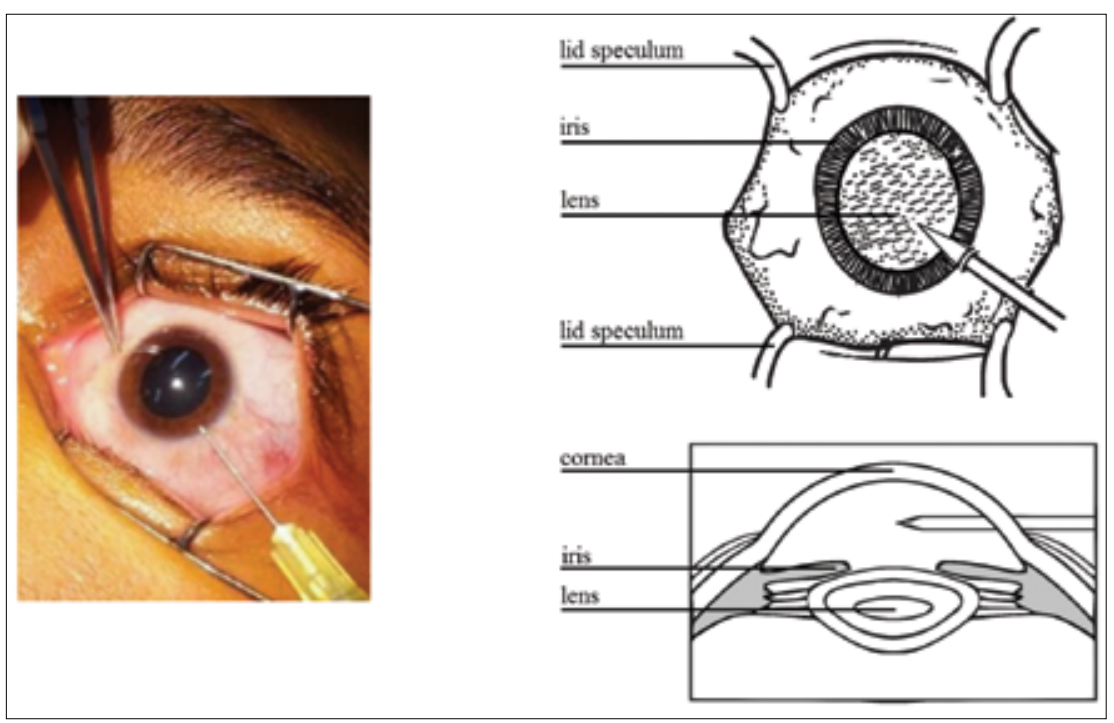

Fig. 1. Photograph and schematic overview of anterior chamber paracentesis for the aspiration of aqueous humor.

of intraocular pressure and diagnosis of suspected intraocular infections, metastasis and lymphoma. ${ }^{[5,6]}$ The two key diagnostic tests of aqueous humor are pathogenspecific serological examination of paired ocular fluid and serum samples, and polymerase chain reaction (PCR) testing of the ocular fluid sample. In serological examination, intraocular pathogen-specific IgG is measured and compared with serum IgG levels (Goldmann-Witmer coefficient) to differentiate between intraocular production of antibody and passive leakage from the blood as proxy for infection, whereas PCR identifies pathogenspecific nucleic acids. ${ }^{[9]}$ In infectious uveitis, pathogen-specific nucleic acids and $\operatorname{IgG}$ production are commonly detectable at different times after the onset of disease. During the early phase, nucleic acids are detectable within days after the onset of disease, followed by detection of intraocular IgG levels. Whereas pathogen nucleic acids commonly become undetectable 2 weeks after the onset of disease, specific antibodies remain detectable for many weeks in aqueous humor. ${ }^{[9]}$ The two assays are therefore complementary, and contribute considerably to the differential diagnosis of infectious uveitis. ${ }^{[4-6,9,10]}$ Identification of the triggering pathogen was established by serological examination and PCR in $60 \%$ of HIV-infected individuals presenting with undefined posterior uveitis, whereas PCR provided a final diagnosis in 39\% of cases in which the initial diagnosis of the causative pathogen was uncertain. ${ }^{[4,10]}$ Furthermore, treatment was altered on the basis of PCR results in $20 \%$ of patients with posterior uveitis of suspected infectious origin in a study from the USA. ${ }^{[6]}$

\section{Anterior chamber para- centesis in uveitis}

Anterior chamber paracentesis is a safe procedure that can be performed in a consultation room with a slit-lamp. ${ }^{[1,12]}$ Three studies have reported on the safety of this procedure in diagnosing uveitis. ${ }^{[11-13]}$ Only a few nonserious complications occurred, including traumatic hyphaema (5 cases/1 000 procedures), referring to bleeding in the anterior chamber that may cause blurred vision, but usually resolves spontaneously or is easily treatable with topical eyedrops (e.g. topical steroids); similarly, injection of air into the anterior chamber (4 cases/ 1000 procedures) may cause blurred vision, but is usually selflimiting. ${ }^{[11-13]}$

Uveitis is a serious condition resulting in severe visual impairment and even blindness if not treated promptly and adequately. In SA, referral from lower levels of healthcare to a regional ophthalmology unit for further management and initiation of (empirical) treatment is indicated. However, even in these units treatment outcomes may be poor owing to the low predictive value of the patient's history and clinical characteristics for identifying the cause of the uveitis.

Anterior chamber paracentesis, aspiration and analysis of aqueous humor provide a valuable diagnostic procedure that optimises treatment and subsequent prognosis and poses a very limited risk. We believe that this procedure could be performed in most settings, because a well-trained ophthalmic nurse could perform anterior chamber paracentesis safely in situations where qualified ophthalmologists are not available. Paracentesis is easier to perform than cataract surgery, for which ophthalmic nurses are trained in African countries such as Malawi that lack ophthalmologists. ${ }^{[14]}$ In addition to skills development, strengthening laboratory infrastructure is warranted. Validation of existing diagnostic assays and provision of other resources required to analyse aqueous humor for the most common uveitogenic pathogens should be considered across SA Furthermore, logistic systems such as a cold-sample transport chain require optimisation to ensure a short turnaround time and maximum clinical impact of this diagnostic test. Providing such a diagnostic service 
would be cost-effective, reducing unnecessary use of expensive antimicrobial drugs and avoiding blindness and its associated socioeconomic costs. ${ }^{[15]}$

\section{Conclusion}

We seek to draw attention to the so far unmet need for this valuable diagnostic procedure and to encourage discussion among healthcare providers regarding introduction of anterior chamber paracentesis in the routine work-up of patients with uveitis in SA. Ultimately, these efforts should result in the development of clinical guidelines and a training programme that includes anterior chamber aspiration. This would improve clinical management of uveitis and reduce the burden of avoidable visual impairment and blindness.

Authorship. ES: literature search, design, figure, table and writing; KAL: writing; GSB: literature search and writing; CM: writing; GMGMV: writing and figure; JAM: writing; RPHP: literature search, design, figure, table, and writing. All the authors have seen and approved the content of this article.

Acknowledgements. We thank Prof. Aniki Rothova of the Department of Ophthalmology, Erasmus MC, Rotterdam, The Netherlands, for providing the photo in Fig. 1.

\footnotetext{
1. London NJ, Rathinam SR, Cunningham ET Jr. The epidemiology of uveitis in developing countries. Int
} Ophthalmol Clin 2010;50(2):1-17. [http://dx.doi.org/10.1097/IIO.0b013e3181d2cc6b]
2. Schaftenaar E, van Gorp ECM, Meenken C, et al. Ocular infections in sub-Saharan Africa in the context of high HIV prevalence. Trop Med Int Health 2014;19(9):1003-1014. [http://dx.doi. org/10.1111/tmi.12350]

3. Otiti-Sengeri J. Colebunders R, Kempen JH, Ronald A, Sande M, Katabira E. The prevalence and 3. Otiti-Sengeri J, Colebunders R, Kempen JH, Ronald A, Sande M, Katabira E. The prevalence and
causes of visual loss among HIV-infected individuals with visual loss in Uganda. J Acquir Immune

4. Scheepers MA, Lecuona KA, Rogers G, Bunce C, Corcoran C, Michaelides M. The value of routine polymerase chain reaction analysis of intraocular fluid specimens in the diagnosis of infectious posterior uveitis. ScientificWorldJournal 2013;2013:545149. [http://dx.doi.org/10.1155/2013/545149]

5. Rothova A, de Boer JH, Ten Dam-van Loon NH, et al. Usefulness of aqueous humor analysis for the diagnosis of posterior uveitis. Ophthalmology 2008;115(2):306-131. [http://dx.doi.org/10.1016/j. ophtha.2007.05.014]

6. Harper TW, Miller D, Schiffman JC, Davis JL. Polymerase chain reaction analysis of aqueous and vitreous specimens in the diagnosis of posterior segment infectious uveitis. Am J Ophthalmol 2009;147(1):140-147. [http://dx.doi.org/10.1016/j.ajo.2008.07.043]

7. Abu El-Asrar AM, Abouammoh M, Al-Mezaine HS. Tuberculous uveitis. Int Ophthalmol Clin 2010;50(2):19-39. [http://dx.doi.org/10.1097/IIO.0b013e3181d2ccb9]

8. Hunter RS, Lobo AM. Current diagnostic approaches to infectious anterior uveitis. Int Ophthalmol . Hunter RS, Lobo AM. Current diagnostic approaches to infectious anterior u
Clin 2011;51(4):145-156. [http://dx.doi.org/10.1097/IIO.0b013e31822d6807]

9. De Groot-Mijnes JD, Rothova A, van Loon AM, et al. Polymerase chain reaction and Goldmann9. De Groot-Mijnes JD, Rothova A, van Loon AM, et al. Polymerase chain reaction and Goldmann-
Witmer coefficient analysis are complementary for the diagnosis of infectious uveitis. Am J

10. Danise A, Cinque P, Vergani S, et al. Use of polymerase chain reaction assays of aqueous humor in the differential diagnosis of retinitis in patients infected with human immunodeficiency virus. Clin Infect Dis 1997;24(6):1100-1106. [http://dx.doi.org/10.1086/513625]

11. Cheung CM, Durrani OM, Murray PI. The safety of anterior chamber paracentesis in patients with uveitis. Br J Ophthalmol 2004;88(4):582-583. [http://dx.doi.org/10.1136/bjo.2003.027219]

12. Trivedi D, Denniston AK, Murray PI. Safety profile of anterior chamber paracentesis performed at the slit lamp. Clin Experiment Ophthalmol 2011;39(8):725-728. [http://dx.doi.org/10.1111 /j.1442-9071.2011.02565

13. Van der Lelij A, Rothova A. Diagnostic anterior chamber paracentesis in uveitis: A safe procedure? Br J Ophthalmol 1997;81(11):976-979. [http://dx.doi.org/10.1136/bjo.81.11.976] 14. Palmer JJ, Chinanayi F, Gilbert A, et al. Trends and implications for achieving VISION 2020 human
resources for eye health targets in 16 countries of sub-Saharan Africa by the year 2020. Hum Resour Health 2014;12(1):45. [http://dx.doi.org/10.1186/1478-4491-12-45]

15. De Smet MD, Taylor SRJ, Bodaghi B, et al. Understanding uveitis: The impact of research on visual outcomes. Prog Retin Eye Res 2011;30(6):452-470. [http://dx.doi.org/10.1016/j.preteyeres.2011.06.005]

Accepted 31 May 2015.

\section{This month in the $S A M J$...}

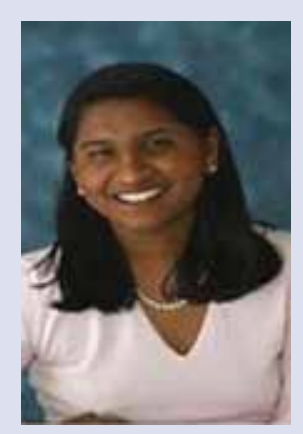

Priscilla Reddy* is Deputy Executive Director in the Population Health, Health Systems and Innovation programme of the Human Sciences Research Council. She holds a $\mathrm{PhD}$ in health promotion and behavioural science from the University of Maastricht in The Netherlands. She has worked and published in the field of tobacco control research since 1992, and her work was used by government to inform its programme of tobacco control measures over the past 23 years. She has conducted controlled trials in smoking cessation in adolescents, and led three Youth Risk Behaviour Surveys and four Global Youth Tobacco Surveys in South Africa. She has also published extensively in behavioural aspects of HIV/AIDS and sexually transmitted disease prevention. She has served on three National Academy of Medicine Committees, reviewing the President's Emergency Plan for AIDS Relief (PEPFAR) Antiretroviral Programme and Tobacco Control in Africa.

*Reddy P, Zuma K, Shisana O, Jonas K, Sewpaul R. Prevalence of tobacco use among adults in South Africa: Results from the first South African National Health and Nutrition Examination Survey. S Afr Med J 2015;105(8):648-655. [http://dx.doi.org/10.7196/SAMJnew.7932]

Dr Erik Schaftenaar,* MD, is a $\mathrm{PhD}$ candidate in the Department of Viroscience, Erasmus MC, Rotterdam, The Netherlands, a resident in ophthalmology at Rotterdam Eye Hospital, and an honorary research associate at Anova Health Institute, Tzaneen, South Africa. The clinical studies for his thesis are part of the Mopani Eye Project, a collaboration between Anova Health Institute and the Department of Viroscience.

*Schaftenaar E, Lecuona KA, Baarsma GS, et al. Anterior chamber paracentesis to improve diagnosis and treatment of infectious uveitis in South Africa. S Afr Med J 2015;105(8):628-630. [http://dx.doi.org/10.7196/SAMJnew.7816]
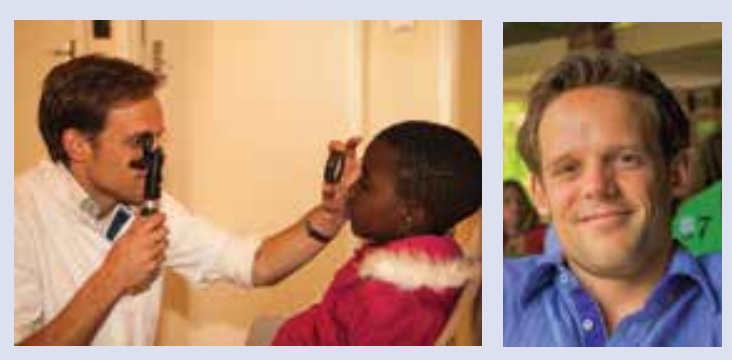